\title{
Adolescents' Willingness and Intentions to Use Contraceptives in Rural Ghana
}

\author{
Sulemana Abubakari, Yeetey A. Enuameh, Emmanuel Mahama, Obed Ernest A. Nettey, \\ George Adjei, Gifty Fosuaa Nuamah, Edward Apraku Anane, Robert Adda, \\ Francis Dzabeng, Seeba Amenga-Etego, Charles Zandoh, Kwaku Poku Asante, \\ Seth Owusu-Agyei \\ Kintampo Health Research Centre, Kintampo, Ghana \\ Email: abubakari.sulemana@kintampo-hrc.org
}

Received 19 October 2015; accepted 16 November 2015; published 19 November 2015

Copyright (C) 2015 by authors and Scientific Research Publishing Inc.

This work is licensed under the Creative Commons Attribution International License (CC BY). http://creativecommons.org/licenses/by/4.0/

c) (i) Open Access

\section{Abstract}

Efforts made to improve the availability and access to family planning services to adolescents in Ghana have not yielded the desired results. Adolescents in the Kintampo Health and Demographic Surveillance System area are no exception. This study explored contraceptive use intentions, preferences and their determinants among adolescents in rural Ghana. This was to contribute evidence towards achieving universal access to reproductive health. A cross-sectional study design was used to collect Sexual and Reproductive Health data in the Kintampo districts in 2011. A total of 1805 female adolescents were randomly sampled from a resident female adolescent population of 16,795. This study used intention and/or willingness of adolescents to use contraceptives as the outcome variable and the explanatory variables were demographic and socio-economic factors. Descriptive and inferential statistical analyses were done. The findings indicated $54.3 \%$ of adolescents' were willing to use contraceptives. Injectable was the most preferred contraceptive method among adolescents $(48.6 \%)$; this was followed by the pill $(29.6 \%)$ with the least being foam or jelly $(0.2 \%)$. The most commonly cited reason for not intending to use contraception was adolescents' opposition to family planning $(31.5 \%)$ followed by a fear of side effects $(25.8 \%)$. Age and education influenced adolescents' willingness to use contraceptives in the future. Formal education of the young generation coupled with knowledge of contraceptive methods could yield positive outcomes for contraceptive use and ultimately reproductive health of the adolescent population in the near future.

\section{Keywords}

Kintampo, Adolescent, Contraceptive, Education, Ghan 


\section{Introduction}

Adolescent females aged 15 - 19 years account for over 14 million births each year, 91 percent of those from low and middle-income countries (LMICs) [1]. Six million adolescent pregnancies are unintended and occur in the context of low contraceptive prevalence [2] [3]. Less than one third of currently married adolescent females in LMICs who want to avoid a pregnancy use a modern method of contraception, and more than 60 percent who would like to avoid or delay pregnancy are not able to do so [4]. Sexual activity of adolescents outside of marriage is increasing, but less than half of those who want to avoid pregnancy are using a modern method of contraception [4]-[6].

Adolescence is the period between the ages of 10 and 19 years when young individuals transit into adulthood [7] [8]. This period is subdivided into early (10 - 14 years) and late (15 - 19 years) adolescence [9] or early (10 13 years), mid- (14 - 15 years) and late (16 - 19 years) adolescence [10] [11]. As per the 2010 population census, adolescents constitute a fifth (22.4\%) of the total population of 24.7 million people in Ghana [12]. In the Kintampo districts covered by the Kintampo Health and Demographic Surveillance System (KHDSS), adolescents also make up a fifth (20.2\%) of the population [13].

Within the past one and half decades, several efforts have been made to make available and accessible sexual and reproductive health (SRH) services to adolescents. Despite these efforts, adolescents still face a number of SRH problems [11]. The birth rate of 15 - 19 year old adolescents in West and Central Africa is estimated as 128 per 1000-more than twice the world average of 50 [14]. These births put female adolescents at a high risk of death or lifelong complications, because they are still not well developed to start child bearing. Many adolescents with unwanted pregnancies tend to go for unsafe abortions due to limited availability and high cost of abortion services. Unsafe abortions contribute significantly to the high rates of morbidity and mortality among young females [14].

According to the 2008 Ghana Demographic and Health Survey (GDHS) about 14\% of all Ghanaian female adolescents have started child bearing, with only $8.0 \%$ of them using contraceptives [15]. The United Nations Population Fund (UNFPA) also reports that, sub-Saharan Africa has the lowest demand (30\%) and use (20\%) of contraceptives among 15 - 19 year olds. They further comment that poor access to family planning (FP) services and negative attitudes of health workers towards adolescent contraceptive use have contributed to high rates of pregnancies among adolescent [16].

This study sought to explore contraceptive use intentions and preferences among female adolescents in two predominantly rural districts in Ghana. The study also examined the factors associated with adolescents' willingness to use contraceptives in the study population. This would contribute evidence towards improving the health of adolescents and meeting MDG 5b of achieving universal access to reproductive health by 2015. This target has been described as the most underachieved of all MDGs [17].

\section{Methods}

\subsection{Study Area}

The Kintampo Health Research Centre (KHRC) administers the KHDSS, which covers the Kintampo North Municipality and the South District in the Brong Ahafo Region of Ghana. The districts are mainly rural and their capitals, Kintampo and Jema, are semi-urban [18]. The districts had an estimated population of about 143,287 as at December 2011 [13]. The KHDSS routinely conducts updates on the entire population by collecting data on births, deaths and migrations as well as other demographic and health information.

\subsection{Study Design, Sampling and Data Collection}

The KHDSS conducted a SRH survey (cross-sectional study design) from July to December 2011. Details of the sampling procedure for the SRH survey is published elsewhere [19]. Data for this manuscript was drawn from information gathered with the female SRH data collection tool. A sample of 1,805 females aged 10 to 19 was randomly selected from a resident female adolescent population of 16,795 within the KHDSS as of July 2011 [13].

As shown in the Appendix, a structured questionnaire consisting of close-ended questions was used in the course of the survey. The questionnaire enquired from respondents' whether they will use a contraceptive method to delay or avoid pregnancy at any time in the future. Respondents who responded "yes" were further 
asked which contraceptive method they preferred to use. On the other hand, those who responded "no" were further asked the main reason for not wanting to use a contraceptive method. In addition, respondents who gave their reason as not being married were further asked whether they would ever use a contraceptive method if they were married. Questionnaires were administered by trained fieldworkers, and interviews were conducted in privacy at the respondent's place of residence. Interviews were done one-on-one with the respondents in the local language. Fieldworkers briefly introduced the study. They translated the questions in the same way to ensure consistency. One question was asked at a time and they followed through the instructions on the questionnaire.

\subsection{Data Management and Analyses}

Field supervisors checked all the forms manually for completeness and consistency. Range and consistency checks were performed and the forms were double entered on computers using Microsoft visual FoxPro (version 9.0) data management software. Discrepancies were resolved by reference to the original forms and field manual, which was used for training the data collectors. Data analyses were performed using STATA version 11.2 [20]. Socio-demographic characteristics of respondents that were categorical in nature were summarized as proportions while continuous variables were summarized as means based on the nature of the distribution. Background information including age, highest educational level attained, marital status and household assets of study subjects was extracted from the KHDSS database. The outcome variables of interest in this study were the intention and/or willingness of adolescents to use contraceptives, as well as adolescents preferred contraceptive and the main reasons for not using contraceptives. Explanatory variables of interest were demographic and socio-economic factors of age, highest educational attainment, household wealth quintile, ethnicity, religion, occupation, place of residence (rural/urban) and district of residence. Household asset data was used to determine the household wealth quintile (i.e. using the Principal Component Analysis) to serve as a proxy for socio-economic status. The categories of the wealth quintile were most poor, more poor, poor, less poor and least poor. Univariate and Multivariate logistic regression models were used to identify respondent characteristics that predicted willingness of adolescents to use contraceptives.

\subsection{Ethical Review}

Prior approval for the study was obtained from the KHRC Institutional Ethics Committee. Respondents were primed and educated on the sensitive issues envisaged in the questionnaire to reduce any uneasiness that could be related to providing information on SRH issues. Participants who voluntarily signed or thumb printed an informed consent or assent form after the study was explained to them were interviewed. The parents or guardians of persons less than 18 years consented after the minors have given their assent. As part of measures to ensure confidentiality, the data is securely stored at the KHRC data bank and only authorized KHRC personnel are provided access.

\section{Results}

\subsection{Socio-Demographic Characteristics of Respondents}

The findings in this section were based on data captured in Table 1. A total of 1,421 female adolescents were included in this study after data cleaning. They were categorized into early (10 - 13 years), mid- (14 - 15 years) and late (16 - 19 years) adolescence. About one quarter (24.8\%) of the respondents were aged 10 - 13, a little over a fifth (20.4\%) were 14 to 15 years and more than half (54.8\%) were 16 to 19 years. Less than a fifth of the adolescents (15.6\%) had no formal education. Almost half (47.9\%) had primary education, over a fifth (23.2\%) had completed middle or junior high school and 13.3 percent had completed senior high school or tertiary education.

Most adolescents (86.4\%) were single at the time of the survey. The Northern tribes constituted half (49.8\%) of the ethnic groups in the study population, followed by the Akan (22\%), the Mo (12 percent) and other tribes (16.2\%). Over half (55.2\%) of the respondents belonged to the Christian faith, while close to a third (27.7\%) were Muslims. Close to a third of the respondents (32.4\%) were not employed. About two-thirds (63 percent) of the respondents were from rural communities and twenty three percent $(22.5 \%)$ belonged to the least poor households. 
Table 1. Socio-demographic and economic characteristics of respondents $(\mathrm{N}=1,421)$.

\begin{tabular}{|c|c|c|}
\hline Characteristics & Number & $\%$ \\
\hline \multicolumn{3}{|l|}{ Age of respondents } \\
\hline $10-13$ & 352 & 24.8 \\
\hline $14-15$ & 290 & 20.4 \\
\hline $16-19$ & 779 & 54.8 \\
\hline \multicolumn{3}{|l|}{ Educational level } \\
\hline No education & 221 & 15.6 \\
\hline Primary & 680 & 47.9 \\
\hline Middle/JHS & 331 & 23.2 \\
\hline SHS and above & 189 & 13.3 \\
\hline \multicolumn{3}{|l|}{ Ethnicity } \\
\hline Akan & 312 & 22.0 \\
\hline Mo & 171 & 12.0 \\
\hline Northern & 707 & 49.8 \\
\hline Other & 231 & 16.2 \\
\hline \multicolumn{3}{|l|}{ Religion } \\
\hline Christian & 785 & 55.2 \\
\hline Moslem & 393 & 27.7 \\
\hline Other religion & 107 & 7.5 \\
\hline Not known & 136 & 9.6 \\
\hline \multicolumn{3}{|l|}{ Occupation } \\
\hline Not employed & 461 & 32.4 \\
\hline Employed & 34 & 2.4 \\
\hline Farmer, labourer, domestic & 101 & 7.1 \\
\hline Minor & 688 & 48.4 \\
\hline Not known & 137 & 9.7 \\
\hline \multicolumn{3}{|l|}{ Marital status } \\
\hline Married & 21 & 1.5 \\
\hline Living together & 172 & 12.1 \\
\hline Single & 1228 & 86.4 \\
\hline \multicolumn{3}{|l|}{ Place of residence } \\
\hline Rural & 906 & 63.8 \\
\hline Urban & 515 & 36.2 \\
\hline \multicolumn{3}{|l|}{ Household wealth quintiles } \\
\hline Most poor & 258 & 18.1 \\
\hline More poor & 260 & 18.3 \\
\hline Poor & 280 & 19.7 \\
\hline Less poor & 304 & 21.4 \\
\hline Least poor & 319 & 22.5 \\
\hline
\end{tabular}




\subsection{Adolescents' Willingness to Use Contraceptives at the Time of the Study}

As shown in Table 2(a), about six (62.4\%) out of ten of the late adolescents were willing to use contraceptives to delay or avoid pregnancy compared to about five (51.2\%) and four (38.8\%) out of ten for the mid and early adolescents respectively. More adolescents with no education compared to those with some education were unsure of current use, as were those with northern ethnic background compared to other ethnic groups. A lot more adolescents residing in rural communities compared to those in urban said they were unsure of using contraceptives as at the time of the survey.

Table 2. Adolescents future contraceptive use intentions and willingness to use contraceptive to delay or avoid pregnancy by socio-demographic and economic characteristics.

\begin{tabular}{|c|c|c|c|c|c|c|}
\hline \multirow{2}{*}{$\begin{array}{c}\text { Socio-demographic and } \\
\text { economic variable }\end{array}$} & \multicolumn{3}{|c|}{$\begin{array}{l}\text { a. Willingness of adolescents to use contraceptive } \\
\text { to delay or avoid pregnancy }(\mathrm{N}=1395)\end{array}$} & \multicolumn{3}{|c|}{$\begin{array}{l}\text { b. Intention of adolescents to use contraceptives } \\
\text { if they were married }(N=223)\end{array}$} \\
\hline & Yes (\%) & No (\%) & Not known (\%) & Yes (\%) & No (\%) & Not known (\%) \\
\hline $10-13$ & 134 (38.8) & 147 (42.6) & $64(18.6)$ & $10(13.7)$ & $40(54.8)$ & $23(31.5)$ \\
\hline $14-15$ & $146(51.2)$ & $114(40.0)$ & $25(8.8)$ & $11(24.4)$ & $27(60.0)$ & $7(15.6)$ \\
\hline $16-19$ & 477 (62.4) & 239 (31.2) & 49 (6.4) & $44(41.9)$ & 46 (43.8) & $15(14.3)$ \\
\hline Total & 757 (54.3) & $500(35.8)$ & $138(9.9)$ & 65 (29.1) & 113 (50.7) & $45(20.2)$ \\
\hline \multicolumn{7}{|l|}{ Educational level } \\
\hline No education & $73(34.0)$ & $96(44.6)$ & $46(21.4)$ & $5(10.6)$ & $24(51.1)$ & 18 (38.3) \\
\hline Primary & 355 (52.8) & $251(37.4)$ & $66(9.8)$ & 33 (29.5) & $60(53.6)$ & 19 (16.9) \\
\hline Middle/JHS & 216 (65.9) & $101(30.8)$ & $11(3.4)$ & 20 (51.3) & 17 (43.6) & $2(5.1)$ \\
\hline SHS and above & $113(62.8)$ & 52 (28.9) & $15(8.3)$ & $7(28.0)$ & $12(48.0)$ & $6(24.0)$ \\
\hline Total & 757 (54.3) & $500(35.8)$ & $138(9.9)$ & 65 (29.1) & 113 (50.7) & $45(20.2)$ \\
\hline \multicolumn{7}{|l|}{ Ethnicity } \\
\hline Akan & $185(60.3)$ & $105(34.2)$ & $17(5.5)$ & 14 (38.9) & $19(52.8)$ & $3(8.3)$ \\
\hline Mo & $101(61.6)$ & 48 (29.3) & $15(9.2)$ & $6(28.6)$ & $12(57.1)$ & $3(14.3)$ \\
\hline Northern & $340(48.6)$ & $268(38.4)$ & $91(13.0)$ & $33(26.0)$ & $61(48.0)$ & $33(26.0)$ \\
\hline Other & 131 (58.2) & 79 (35.1) & 15 (6.7) & $12(30.8)$ & 21 (53.9) & $6(15.3)$ \\
\hline Total & 757 (54.3) & $500(35.8)$ & 138 (9.9) & 65 (29.1) & 113 (50.7) & $45(20.2)$ \\
\hline \multicolumn{7}{|l|}{ Religion } \\
\hline Christian & $443(57.4)$ & $268(34.7)$ & $61(7.9)$ & $41(36.3)$ & $54(47.8)$ & 18 (15.9) \\
\hline Moslem & $195(50.4)$ & $268(34.7)$ & 61 (7.9) & $16(24.6)$ & 31 (47.7) & $18(27.7)$ \\
\hline Other religion & $51(48.6)$ & 39 (37.1) & $15(14.3)$ & $3(18.8)$ & $9(56.2)$ & $4(25.0)$ \\
\hline Not known & $68(52.3)$ & $53(40.8)$ & 9 (6.9) & $5(17.2)$ & 19 (65.5) & $5(17.2)$ \\
\hline Total & 757 (54.3) & $500(35.8)$ & 138 (9.9) & 65 (29.1) & 113 (50.7) & $45(20.2)$ \\
\hline \multicolumn{7}{|l|}{ Occupation } \\
\hline Not employed & 272 (59.5) & $148(32.4)$ & $37(8.1)$ & $28(40.0)$ & 30 (42.9) & $12(17.1)$ \\
\hline Employed & $25(75.7)$ & $6(18.2)$ & $2(6.1)$ & $2(40.0)$ & $3(60.0)$ & $0(0.0)$ \\
\hline Farmer, labourer & $56(56.0)$ & $37(37.0)$ & $7(7.0)$ & $5(33.3)$ & $7(46.7)$ & $3(20.0)$ \\
\hline Minor & 335 (49.7) & $256(38.0)$ & $83(12.3)$ & $25(24.0)$ & $54(52.0)$ & $25(24.0)$ \\
\hline Not known & 69 (52.7) & $53(40.5)$ & $9(6.9)$ & $5(17.2)$ & $19(65.6)$ & $5(17.2)$ \\
\hline Total & 757 (54.3) & $500(35.8)$ & 138 (9.9) & 65 (29.1) & 113 (50.7) & $45(20.2)$ \\
\hline \multicolumn{7}{|l|}{ Marital status } \\
\hline Married & 13 (61.9) & 7 (33.3) & $1(4.8)$ & - & - & - \\
\hline Living together & 125 (72.7) & $41(23.8)$ & $6(3.5)$ & $5(41.7)$ & $5(41.7)$ & $2(16.6)$ \\
\hline Single & 619 (51.5) & $452(37.6)$ & 131 (10.9) & $60(28.4)$ & $108(51.2)$ & $43(20.4)$ \\
\hline Total & 757 (54.3) & $500(35.8)$ & 138 (9.9) & $65(29.1)$ & 113 (50.7) & $45(20.2)$ \\
\hline \multicolumn{7}{|l|}{ Place of residence } \\
\hline Rural & 445 (49.7) & $353(39.4)$ & 97 (10.9) & $51(28.8)$ & $86(48.6)$ & $40(22.6)$ \\
\hline Urban & $312(62.4)$ & 147 (29.4) & $41(8.2)$ & $14(30.4)$ & 27 (58.7) & 5 (10.9) \\
\hline Total & 757 (54.3) & $500(35.8)$ & $138(9.9)$ & 65 (29.1) & 113 (50.7) & $45(20.2)$ \\
\hline \multicolumn{7}{|l|}{ Wealth quintiles } \\
\hline Most poor & 123 (49.2) & $98(39.2)$ & $29(11.6)$ & $12(27.9)$ & $23(53.5)$ & 8 (18.6) \\
\hline More poor & $119(46.5)$ & $106(41.4)$ & 31 (12.1) & $12(24.5)$ & 26 (53.1) & $11(22.5)$ \\
\hline Poor & 151 (55.3) & $94(34.4)$ & $28(10.3)$ & $8(20.5)$ & $19(48.7)$ & $12(30.8)$ \\
\hline Less poor & $160(53.0)$ & 117 (38.7) & $25(8.3)$ & $15(30.6)$ & $26(53.1)$ & 8 (16.3) \\
\hline Least poor & $204(65.0)$ & $85(27.1)$ & 25 (7.9) & 18 (41.9) & $19(44.1)$ & $6(14.0)$ \\
\hline Total & 757 (54.3) & $500(35.8)$ & 138 (9.9) & 65 (29.1) & $113(50.7)$ & $45(20.2)$ \\
\hline
\end{tabular}




\subsection{Adolescents' Intention to Use Contraceptives in the Future}

Adolescents' intention to use contraceptives in future as shown in Table 2(b) follows a similar pattern to their willingness to use contraceptives at the time of the survey shown in Table 2(a). About four out of ten of the late adolescents intended to use contraceptives when they got married. For the early and mid-adolescents, about one and two respectively out of ten intended to use contraceptives when they were married. More of the early adolescents (31.5\%) compared to the mid (15.6\%) and late (14.3\%) adolescents did not know whether they would use contraceptives when they got married. More adolescents with no education compared to those with some education were not certain of their intention to use contraceptives. Also, more adolescents of northern ethnicity compared to other ethnic groups did not know whether they would use contraceptives in the future. Furthermore, more Muslim adolescents compared to other religions were uncertain of their intention to use contraceptives in the future. Adolescents residing in rural communities (22.6\%) compared to those in urban (10.9\%) did not know whether they intended to use contraceptives.

\subsection{Adolescents' Preferred Contraceptive Methods}

Injectables were the most preferred contraceptive method among adolescents (48.6\%); this was followed by the pill (29.6\%) with the least being foam or jelly (0.2\%) as shown in Table 3(a). However, the early adolescents equally liked the injectables and the pills, $43.4 \%$ apiece. On the other hand, $47.1 \%$ and $28.1 \%$ of the mid adolescents would prefer to use the injectables and the pills respectively while $50.1 \%$ and $26.9 \%$ of the late adolescents would prefer to use the injectables and the pills in that order.

Table 3. Adolescents preferred contraceptive methods and main reasons for not using contraceptive method by age-group.

\begin{tabular}{|c|c|c|c|c|}
\hline \multirow{2}{*}{ a. Preferred contraceptive method $(\mathrm{N}=663)$} & \multicolumn{4}{|c|}{ Age-group (\%) } \\
\hline & $10-13$ & $14-15$ & $16-19$ & Total \\
\hline Female sterilization & $2(2.0)$ & $4(3.3)$ & $3(0.7)$ & $9(1.4)$ \\
\hline Male sterilization & $3(3.1)$ & $9(7.4)$ & $38(8.6)$ & $50(7.5)$ \\
\hline Pill & $43(43.4)$ & $34(28.1)$ & 119 (26.9) & $196(29.6)$ \\
\hline IUD & $0(0.0)$ & $1(0.8)$ & $6(1.4)$ & $7(1.1)$ \\
\hline Injectables & $43(43.4)$ & $57(47.1)$ & $222(50.1)$ & $322(48.6)$ \\
\hline Implants & $6(6.1)$ & $5(4.1)$ & $23(5.2)$ & $34(5.1)$ \\
\hline Male condom & $0(0.0)$ & $4(3.3)$ & $23(5.2)$ & $27(4.1)$ \\
\hline Female condom & $2(2.0)$ & $6(5.0)$ & $5(1.1)$ & $13(2.0)$ \\
\hline Diaphragm & $0(0.0)$ & $1(0.8)$ & $3(0.7)$ & $4(0.6)$ \\
\hline Form/Jelly & $0(0.0)$ & $0(0.0)$ & $1(0.2)$ & $1(0.2)$ \\
\hline Total & $99(100.0)$ & $121(100.0)$ & $443(00.0)$ & $663(00.0)$ \\
\hline $\begin{array}{l}\text { b. Main reasons for not intending to use } \\
\text { contraceptive method }(N=476)\end{array}$ & $10-13$ & $14-15$ & $16-19$ & Total \\
\hline Not married & 37 (26.6) & 19 (17.8) & 32 (13.9) & 88 (18.5) \\
\hline Not having sex & $16(11.5)$ & $5(5.6)$ & $14(6.1)$ & $36(7.6)$ \\
\hline Infrequent sex & $0(0.0)$ & $0(0.0)$ & $5(2.2)$ & $5(1.1)$ \\
\hline Menopausal/ Hysterecto & $0(0.0)$ & $0(0.0)$ & $1(0.4)$ & $1(0.2)$ \\
\hline Lactational amenorrhea & $0(0.0)$ & $0(0.0)$ & $1(0.4)$ & $1(0.2)$ \\
\hline Respondent opposed & $40(28.8)$ & $26(24.3)$ & $84(36.5)$ & $150(31.5)$ \\
\hline Others opposed & $0(0.0)$ & $1(0.9)$ & $2(0.9)$ & $3(0.6)$ \\
\hline Religious prohibition & $3(2.2)$ & $2(1.9)$ & $3(1.3)$ & $8(1.7)$ \\
\hline Knows no method & $20(14.4)$ & $11(10.3)$ & $9(3.9)$ & $40(8.4)$ \\
\hline Knows no source & $4(2.9)$ & $2(1.9)$ & $3(1.3)$ & $9(1.9)$ \\
\hline Health concerns & $0(0.0)$ & $0(0.0)$ & $4(1.7)$ & $4(0.8)$ \\
\hline Fear of side effects & $18(13.0)$ & 39 (36.5) & $66(28.7)$ & $123(25.8)$ \\
\hline Cost too much & $0(0.0)$ & $0(0.0)$ & $1(0.4)$ & $1(0.2)$ \\
\hline Interferes with body & $0(0.0)$ & $0(0.0)$ & $2(0.9)$ & $2(0.4)$ \\
\hline Other & $1(0.7)$ & $1(0.9)$ & $3(1.3)$ & $5(1.1)$ \\
\hline Total & $139(100.0)$ & $107(100.0)$ & $230(100.0)$ & $476(100.0)$ \\
\hline
\end{tabular}




\subsection{Adolescents' Reasons for Not Intending to Use Contraceptives in the Future}

For adolescents who did not intend using contraceptives in the future, the most commonly cited reasons were opposition to FP (31.5\%), followed by a fear of side effects $(25.8 \%)$ with the least being cost $(0.2 \%)$, and the use of lactational amenorrhea (0.2\%). However, among the mid adolescents fear of side effects (36.5\%) contributed more than opposition to FP (24.3\%) as reasons for not intending to use contraceptives as shown in Table 3(b).

\subsection{Predictors of Adolescents' Willingness to Use Contraceptives to Delay or Avoid Future Pregnancies}

Results of potential determinants of adolescents' willingness to use contraceptive methods from univariate and multivariate logistic regression models are presented in Table 4. Age, level of education, religion, marital status and household wealth quintiles of respondents were significantly associated with adolescents' willingness to use contraceptives. Late adolescents were significantly more willing to use contraceptives than early adolescents (OR = 2.61, 95\% CI: 2.01 - 3.89; P < 0.01). Adolescents with Senior High School (SHS) education and above were significantly more willing to use contraceptives than those with no education (OR = 3.28, 95\% CI: 2.17 4.96, $\mathrm{P}<0.01$ ). Adolescents from the least poor households were significantly more willing to use contraceptives than those from the poorest households ( $\mathrm{OR}=1.91,95 \% \mathrm{CI}: 1.36-2.69$; $\mathrm{P}<0.01)$. Being in late adolescence and the level of education remained the strongest independent predictors of adolescents' willingness to use contraceptives after multivariate logistic regression. The odds of contraceptive use of those with Senior High School (SHS) education and above being more than two folds that among adolescents without any formal education as depicted in Table 4.

Table 4. Univariate and multivariate logistic regression of adolescents who are willing to use contraceptive to delay or avoid pregnancy by socio-demographic and economic characteristics.

\begin{tabular}{|c|c|c|c|c|c|c|c|}
\hline Characteristics & n (\%) & Crude OR & $95 \%$ CI & $P$ value & Adjusted OR & $95 \% \mathrm{CI}$ & $P$ value \\
\hline \multicolumn{8}{|l|}{ Age of respondents } \\
\hline $10-13$ & 134 (38.8) & 1 & & & 1 & & \\
\hline $14-15$ & $146(51.2)$ & 1.65 & $(1.20 .2 .27)$ & $<0.001$ & 1.30 & $(0.93,1.83)$ & $0.128^{*}$ \\
\hline $16-19$ & $477(62.4)$ & 2.61 & $(2.01,3.89)$ & & 1.73 & $(1.28,2.34)$ & $<0.001^{*}$ \\
\hline \multicolumn{8}{|l|}{ Educational level } \\
\hline No education & 355 (52.8) & 1 & & & 1 & & \\
\hline Primary & $216(65.9)$ & 2.18 & $(1.58,3.00)$ & & 1.83 & $(1.30,2.57)$ & $0.001^{*}$ \\
\hline Middle/JHS & $113(62.8)$ & 3.75 & $(2.61,5.39)$ & $<0.001$ & 2.27 & $(1.51,3.43)$ & $<0.001^{*}$ \\
\hline SHS and above & $73(34.0)$ & 3.28 & $(2.17,4.96)$ & & 2.31 & $(1.48,3.60)$ & $<0.001^{*}$ \\
\hline \multicolumn{8}{|l|}{ Religion } \\
\hline Christian & $443(57.4)$ & 1 & & & 1 & & \\
\hline Moslem & $195(50.4)$ & 0.75 & $(0.59,0.96)$ & 0.069 & 0.84 & $(0.63,4.41)$ & $0.183^{* *}$ \\
\hline Other religion & $51(48.6)$ & 0.70 & $(0.47,1.05)$ & & 0.79 & $(0.52,1.21)$ & $0.283^{* *}$ \\
\hline Not known & $68(52.3)$ & 0.81 & $(0.56,1.18)$ & & 0.90 & $(0.61,1.33)$ & $0.595^{* *}$ \\
\hline \multicolumn{8}{|l|}{ Marital status } \\
\hline Married & 13 (61.9) & 1 & & & 1 & & \\
\hline Living together & 125 (72.7) & 1.64 & $(0.64,4.20)$ & $<0.001$ & 1.66 & $(0.63,4.41)$ & $0.306^{*}$ \\
\hline Single & $619(51.5)$ & 0.65 & $(0.27,1.59)$ & & 0.84 & $(0.33,2.11)$ & $0.706^{*}$ \\
\hline \multicolumn{8}{|c|}{ Household wealth quintiles } \\
\hline Most poor & $123(49.2)$ & 1 & & & 1 & & \\
\hline More poor & $119(46.5)$ & 0.90 & $(0.63,1.27)$ & 0.001 & 0.89 & $(0.62,1.28)$ & $0.534^{*}$ \\
\hline Poor & $151(55.3)$ & 1.28 & $(0.91,1.80)$ & & 1.24 & $(0.87,1.77)$ & $0.242^{*}$ \\
\hline Less poor & $160(53.0)$ & 1.16 & $(0.83,1.63)$ & & 1.09 & $(0.77,1.55)$ & $0.613^{*}$ \\
\hline Least poor & $204(65.0)$ & 1.91 & $(1.36,2.69)$ & & 1.72 & $(1.20,2.45)$ & $0.003^{*}$ \\
\hline
\end{tabular}

OR: Odds ratio; CI: Confidence Interva; (\%): proportion of adolescent in each sub-group who are willing to use contraceptive to delay or avoid pregnancy; ${ }^{*}$ Likelihood ratio p-value $<0.001 ;{ }^{* *}$ Likelihood ratio $\mathrm{p}$-value $=0.482$. 


\section{Discussions}

Effective FP programs are associated with decreases in maternal mortality and morbidity, infant mortality and abortions among adolescents [21]. The goal of this study was to explore contraceptive use intentions and preferences among adolescents in Kintampo Districts of Ghana. The study also examined the differences and determinants of adolescents' willingness to use contraceptive to delay or avoid pregnancy. Intention to use FP is an important indicator of the potential demand for services [17]. The study found out that more than a third of the adolescents were not willing to use a contraceptive to delay or avoid pregnancy. Also, more than half of the adolescents who were not married did not intend to use contraceptives if they were married. DHS reports from Ghana and Nigeria in 2008 mentioned that 46 and 55 percent respectively of currently married non-users of contraceptives have no intention to use any method in the future [17] [22]. In the current study, older adolescents intended to use contraceptives if they were married and were willing to use contraceptives to delay or avoid pregnancies than their younger ones. These findings indicate the need to increase the level of FP messages and services to target groups, particularly the early and mid-adolescents.

Programme managers are particularly interested in the preferred methods of non-users who reported that they intend to use a FP method in the future. This information is useful in assessing the potential demand for specific methods of FP [21]. The most preferred contraceptive method among adolescents was the injectable, followed by the pill. This is in tandem with preferences of married women from the 2008 GDHS, where the contraceptive method most preferred for future use was injectable (39\%), followed by the pill (21\%), and implants (10\%). This implies that the hormonal contraceptives were more popular while the use of condoms for FP was low, in spite of the burden of STDs and HIV in Ghana including the study area.

An understanding of the reasons behind not intending to use contraceptive methods in the future is crucial to identifying strategies to improve the access, acceptability, and quality of care of family planning services [17]. Findings from the GDHS from the last 10 - 15 years also identified fears of side effect as the main reason women avoided the use of modern contraceptive methods in pregnancy prevention [15] [23]. Findings in the current study point to the fact that the most important reasons for adolescents' non intention to use contraceptives in the future was their opposition to FP and fear of side effects; the latter reason signifying possibly a method-related problem suggesting that the quality or approach to FP services to adolescents in the study area should be revised to meet their needs. Similarly, studies in other sub-Saharan African countries have reported fear of side effects as the main reason for not using contraception [24]-[26]. Only 1.9\% of adolescents who did not intend to use contraception reported "knows no source" and only $0.2 \%$ reported "cost too much" as their main reasons for not intending to use contraception in the future. These findings indicate that adolescents do not perceive availability, accessibility, or cost as major impediments to using contraception.

The level of education plays an important role in the use of modern FP methods. It has been observed in Nigeria that contraceptive use was best predicted by level of education [27] [28]. Similarly, studies elsewhere have shown that the level of education has a strong influence in the acceptance of modern FP methods [29]-[33]. With the univariate and multivariate analysis, the level of education was found to be the strongest predictor of adolescents' willingness to use contraceptive to delay or avoid pregnancy in this study, with the more educated adolescents being much more likely to use FP than the less educated. The study findings point to younger adolescents least willing to either use contraceptives currently or intending to use them in the future.

\section{Limitations to the Study}

This was a cross-sectional study to access the situation on the ground to advise further action on FP care to adolescents. The cross-sectional design of the study prohibits inference of causality so associations were determined. Social desirability compels participants to over-report (give certain desirable responses). For example, an adolescent might report using a condom or otherwise to receive praise or self-satisfaction. Also, sexual issues are very sensitive and could limit free expression on some matters. In view of this, extra questions were asked during interviews to corroborate earlier information provided. We were not able to interview males on all of the questions used in this study, which limited our report to only a female perspective. Future data collection would include male adolescents.

\section{Conclusion}

The study findings point to younger adolescents least willing to either use contraceptives currently or intending 
to use them in the future. The main reasons for non-use were opposition to contraceptive use and fear of their side effects. There is therefore the need to educate adolescents on the diverse types of contraceptive methods, their benefits and anticipated side effects. As educational level was an important predictor of contraceptive use among the study population, ensuring education of the young generation could yield positive outcomes for contraceptive use and ultimately reproduction health of the adolescent population in the near future.

\section{Acknowledgements}

We are most grateful to the survey respondents for granting us interviews for the study. We wish to express our profound gratitude to the Director and management of KHRC for funding and providing administrative support for this study. Our sincere gratitude also goes to SRH staff for conducting the field work. We also acknowledge the support of all staff of KHRC who contributed in diverse ways to make this study a success.

\section{Competing Interest}

The authors declare that they have no competing interest.

\section{References}

[1] Elissa, K., Natalie, G., Peter, A. and Mick, C. (2011) Adolescent Fertility and Family Planning in East Asia and the Pacific: A Review of DHS Reports. Reproductive Health, 8.

http://www.reproductive-health-journal.com/content/pdf/1742-4755-8-11.pdf

[2] Guttmacher Institute (2010) Facts on Sexual and Reproductive Health of Adolescent Women in the Developing World. In Brief. New York.

[3] Singh, S. (1998) Adolescent Childbearing in Developing Countries: A Global Review. Studies in Family Planning, 29, 117-136. http://dx.doi.org/10.2307/172154

[4] Singh, S., Darroch, J., Ashford, L. and Vlassoff, M. (2009) Adding It up: The Costs and Benefits of Investing in Family Planning and Maternal and Newborn Health. Guttmacher Institute and United Nations Population Fund, New York.

[5] United Nations (2002) World Population Monitoring 2002-Reproductive Rights and Reproductive Health: Selected Aspects. Department of Economic and Social Affairs Population Division, New York.

[6] Blanc, A.K. and Way, A.A. (1998) Sexual Behavior and Contraceptive Knowledge and Use among Adolescents in Developing Countries. Studies in Family Planning, 29, 106-116. http://dx.doi.org/10.2307/172153

[7] WHO (2015) Maternal, Newborn, Child and Adolescent Health: Adolescent Development. http://www.who.int/maternal_child_adolescent/topics/adolescence/dev/en/

[8] WHO (2003) Preparing for Adulthood: Adolescent Sexual and Reproductive Health. Progress in Reproductive Health Research, 64, 1-2.

[9] James-Troare, T.A. (2001) Developmentally Based Interventions and Strategies: Promoting Reproductive Health and Reducing Risk among Adolescents. Focus on Young Adults.

[10] Padmavati, M., Sulakhe, R. and Panda, S.K. (2014) Prevalence of RTI/STI Symptoms among Adolescent Girls in an Urban Slum of Sambalpur. Perspectives in Medical Research, 2, 21-23.

[11] Abdul-Rahman, L., Marrone, G. and Johansson, A. (2011) Trends in Contraceptive Use among Female Adolescents in Ghana. African Journal of Reproductive Health, 15, 45-55.

[12] Ghana Statistical Service (2012) 2010 Population and Housing Census Summary Report of Final Results. May, 2012.

[13] Kintampo Health Research Centre (2012) Annual Report.

[14] UNFPA, State of the World Population (2014) The Power of 1.8 Billion Adolescents, Youth and the Transformation of the Future. UNFPA, New York.

[15] Ghana Statistical Service, Ghana Health Service (GHS) and ICF Macro (2009) Ghana Demographic and Health Survey 2008. GSS, GHS, and ICF Macro, Accra.

[16] Senderowitz, J. (1999) Making Reproductive Health Services Youth Friendly. Focus on Young Adults, Pathfinder International, Washington DC.

[17] MDG 5B (2010) A Promise Is a Promise. Universal Access to Reproductive Health. http://www.womendeliver.org/assets/MDG 5b Fact Sheet.pdf

[18] Owusu-Agyei, S., Nettey, O.E.A., Zandoh, C., Sulemana, A., Adda, R., Amenga-Etego, S. and Mbacke, C. (2012) Demographic Patterns and Trends in Central Ghana: Baseline Indicators from the Kintampo Health and Demographic 
Surveillance System. Global Health Action, 5, 1-11.

[19] Enuameh, Y., Nettey, O.E., Mahama, E., Tawiah, C., Boamah, E., Sulemana, A., Adjei, G., Gyaase, S., Asiedu, S.A., Manu, A., Zandoh, C., Asante, K.P. and Owusu-Agyei, S. (2015) Family Planning Needs of Adolescents in Predominantly Rural Communities in the Central Part of Ghana. Open Journal of Preventive Medicine, 5, 269-279. http://dx.doi.org/10.4236/ojpm.2015.56030

[20] StataCorp LP (2009) Statistics/Data Analysis. StataCorp 4905 Lakeway Drive, College Station.

[21] Smith, R., Ashford, L., Gribble, J. and Clifton, D. (2009) Family Planning Saves Lives. 4th Edition, Population Reference Bureau, Washington DC.

[22] National Population Commission (NPC) and ICF Macro (2009) Nigeria Demographic and Health Survey 2008. National Population Commission and ICF Macro, Abuja.

[23] Ministry of Health Ghana and Population Council (2005) Ghana Trend Analysis for Family Planning Services 1993, 1996, 2002. ORC Macro, Calverton, MD.

[24] Fakeye, O. and Babaniyi, O. (1989) Reasons for Non-Use of Family Planning Methods at Ilorin, Nigeria: Male Opposition and Fear of Methods. Tropical Doctor, 19, 114-117.

[25] Bertrand, J.T., Mangani, N., Mansilu, M. and Landry, E.G. (2012) The Use of Factors Influencing Traditional versus Modern Family Methods in Bas Zaire. Studies in Family Planning, 16, 332-341.

[26] Chipeta, E.K., Chimwaza, W. and Kalilani-Phiri, L. (2010) Contraceptive Knowledge, Beliefs and Attitudes in Rural Malawi: Misinformation, Misbeliefs and Misperceptions. Malawi Medical Journal: The Journal of Medical Association of Malawi, 22, 38-41. http://dx.doi.org/10.4314/mmj.v22i2.58790 http://www.pubmedcentral.nih.gov/articlerender.fcgi?artid=3345759\&tool=pmcentrez\&rendertype=abstract

[27] Odimwengu, C.O. (1999) Family Planning Attitude and Use in Nigeria: A Factor Analysis. International Family Planning Perspectives, 25, 86-91. http://dx.doi.org/10.2307/2991946

[28] Orji, E.O. and Onwudiegwu, U. (2002) Prevalence and Determinants of Contraceptive Practice in a Defined Nigerian Population. Journal of Obstetrics \& Gynaecology, 22, 540-543. http://dx.doi.org/10.1080/0144361021000003126

[29] Shapiro, D. and Tambase, B.O. (1994) The Impact of Women's Employment and Education on Contraceptive Use and Abortion in Kinshasa, Zaire. Studies in Family Planning, 25, 96-110. http://dx.doi.org/10.2307/2138087

[30] Gage, A.J. (1995) Women's Socioeconomic Position and Contraceptive Behavior in Togo. Studies in Family Planning, 26, 264-277. http://dx.doi.org/10.2307/2138012

[31] Larsen, U. and Hollos, M. (2003) Women's Empowerment and Fertility Decline among the Pare of Kilimanjaro Region, Northern Tanzania. Social Science \& Medicine, 57, 1099-1115. http://dx.doi.org/10.1016/s0277-9536(02)00488-4

[32] Keele, J.J., Forste, R. and Flake, D.F. (2005) Hearing Native Voices: Contraceptive Use in Matemwe Village, East Africa. African Journal of Reproductive Health, 9, 32-41. http://dx.doi.org/10.2307/3583158

[33] Mubita-Ngoma, C. and Kadantu, C. (2010) Knowledge and Use of Modern Family Planning Methods by Rural Women in Zambia. Curationis, 33, 17-22. www.curationis.org.za/index.php/curationis/article/download/1004/941+\&cd=4\&hl=en \&ct=clnk\&gl=gh 


\section{Appendix}

Set of questions used in the study

Do you think you will use a contraceptive method to delay or avoid Pregnancy at any time in the future?

1. Yes 2. No 8. NK USECON

Which contraceptive method would you prefer to use?
11. Female
12. Male
sterilization
sterilization
13. Pill
14. IUD
15. Injectables
16. Implants

$\begin{aligned} & \text { 17. Male } \\ & \text { condom }\end{aligned}$ condomale
19. Diaphragm
20. Form/Jelly
11. Lactational
12. Rhythm
Amenorrhea
method
13. Withdrawal
14. Other:
88. Unsure/NK 99. NA

WHICHCON

What is the main reason that you think you will not use a contraception method at any time in the future?

NOT MARRIED AND FERTILITY-RELATED REASONS

NOUSECON
11. Not married
12. Not having sex
13. Infrequent sex
14. Menopausal/Hysterectomy
15. Subfecund/Infecund
16. Lactational amenorrhea

\section{OPPOSITION TO USE AND LACK OF KNOWLEDGE}
19. Respondent opposed
20. Husband/Partner opposed
21. Others opposed
22. Religious prohibition
23. Knows no method
24. Knows no source

\section{METHOD-RELATED REASONS}
25. Health concerns
26. Fear of side effects
27. Lack of access/Too far
28. Cost too much
29. Interferes with body

30. Other:

88. NK

99. NA

[Ask question 4.13. if question 4.12 is 11. Not married]

Would you ever use a contraceptive method if you were married?

1. Yes 2. No 3. NK 9. NA EVERCON 